\title{
Suggesting Indicators of Superficiality and Purity in Verbal Aggressiveness: An Application in Adult Education Class Networks of Prison Inmates
}

\author{
Alexandra Bekiari, Nikolaos Hasanagas \\ Faculty of Physical Education and Sports Science, University of Thessaly, Thessaly, Greece \\ Email:sandrab@pe.uth.gr,n.hasanagas@gmail.com \\ Received 21 February 2016; accepted 27 March 2016; published 30 March 2016 \\ Copyright (C) 2016 by authors and Scientific Research Publishing Inc. \\ This work is licensed under the Creative Commons Attribution International License (CC BY). \\ http://creativecommons.org/licenses/by/4.0/

cc) (i) Open Access

\begin{abstract}
Aim of this research is to suggest indicators, based on social network analysis, that distinguish superficial, idiosyncratic and strategic verbal aggressiveness. Two classes of an adult education school (at secondary level) in a prison have been selected as network samples (A class $=23$ and B class $=12$ prisoners). Complete network analysis has been applied, using standardized questionnaires. The network variables have further processed through Pearson correlation. Indicators of superficial and pure roles, particularly incremental and proportional behavior, have been applied in two forms of verbal aggressiveness (criticism and threatening). The superficial behavior (SB: outdegree of verbal aggressiveness) seems to be a quite sensitive indicator, as it presents correlations with various other relational forms of familiarity, aggressiveness and appreciation/socialization. The incremental behavior (IB: difference of received from outgoing actions) is also a sensitive indicator, revealing, however, different results. Pure aggressiveness (in terms of difference) seems to be related with quite different causes and/or occasions than the superficial aggressiveness. Incremental behavior is likely to be at first place driven by the idiosyncrasy rather than by exogenous factors and seems to constitute a completely different notion than the SB. The proportional behavior (PB: ration of outgoing to the received actions) of aggression is a quite insensitive indicator, as it depends only on a few behavioral variables. It seems to reveal a rational strategy of adaptability. Thus, it characteristically differs from the indicators of superficiality (expressing reciprocity patterns) and of the incremental aggressiveness (expressing individualism).
\end{abstract}

\section{Keywords}

Verbal Aggressiveness, Prisoners, Social Network Analysis, Superficial, Incremental, Proportional Behavior 


\section{Introduction}

Everyone can realize that there is a difference between "I attack because it is the usual practice", "I attack because I am warlike" and "I attack because this is the rational strategy depending on the conditions". The first case could reasonably be perceived as "superficial", while the second one as "idiosyncratic" and the third one as "strategic". Aim of this research is to suggest indicators, based on social network analysis, that distinguish superficial, idiosyncratic and strategic aggressiveness.

Verbal aggressiveness is a destructive communication feature that is considered to erode human relationships [1]. Verbal aggression is defined as the attack a person's self-concept of the other in order to cause psychological pain as humiliation, shame, depression, as well as additional negative feelings about themselves [1]-[4]. The ways in which it can manifest itself are attacks on the character, in ability, in appearance and in the background, ridicule, threats, profanity, curses, quips and gestures [2] [5]-[7]. The verbally aggressive people, without considering the harmful messages, they appear to exhibit certain sensitivity to pain caused by verbal aggressiveness, in contrast to other people. The findings of the majority of investigations have shown that the trait of verbal aggression leads to negative results regardless of the type of relationship of respondents [8]-[11].

Within the dynamic of a class where students receive the verbal aggression of their teachers, they indicate lower levels of motivation, satisfaction, and a more hostile learning environment [12]-[15]. Additionally, students consider teachers verbally aggressive as less reliable than teachers avoid deconstructive communication in the classroom [9] [12] [16]. It is understood that aggressive communication between teachers and students or only between students tends to significantly affect learning, behavior, thinking, motivation, socialization and attractiveness [12] [17]-[20].

Concerning prison research, there is also plenty of studies. It is found that prisoners are satisfied having aggressive behavior to be acceptable to the society of jail [21]. It has been supported that a negative relationship appears between verbal aggressiveness and communication satisfaction to young inmates in prison [23]. Also, young prisoners who engage physical aggression were also higher in verbal aggression. Moreover, younger prisoners use the technique of older prisoners to deter their attacks being aggressive either with verbal or physical violence [22].

However, these studies mainly focus on the use of aggressiveness and its acceptance in prison and not on its general impacts on or interaction with various types of relation among prisoners. Of course, it was not tried to test subtly differentiated indicators in order to reveal latent interactions or intentions.

The innovation of the present paper consists in the fact that it focuses not on the classic single-dimensioned relation of aggressiveness from one part to another (e.g. from one student to another, from instructor to students, etc) but it involves the mutuality of aggressiveness (received and practiced) among individuals. In this framework, new indicators integrating network variables are suggested.

Moreover, this research analyzes samples of prisoners within a jail. This is also an innovative peculiarity of this research, as the accessibility to prisoners for exploring their relations to each other is quite difficult to the researchers, normally because of the reluctance of the prisoners to collaborate. The particular group of prisoners was an exceptional and ideal case.

\section{Method}

\subsection{Sampling and Process}

Prisoners have been selected as a sample in this research. For reasons of discretion, no further information can be provided about the prisoners and even not about the prison. This absolute confidentiality was a necessary prerequisite for assuring the collaboration of the prisoners. The lack of this information should not necessarily be regarded as a weakness of this research as its purpose is not to provide descriptive or qualitative information about the correctional system of a country or criminological analyses but just to test network indicators under the mostly appropriate conditions (which in this research are the conditions of pressure and physical restriction assured by any correctional facility in the world).

Two classes of an adult education school (at secondary level) in a prison have been selected as network samples. As known, network samples are non-random samples but this is not a methodical weakness, as this research does not aim at producing descriptive but only analytic statistics. The A class was consisted of 23 and the B class of 12 prisoners, constituting two networks of 23 and 12 nodes, respectively. Complete network analysis 
has been applied on these two samples. The primary data (relations between prisoners) were collected by the standardized questionnaires. The questions were concerning the following forms of relations: 1) familiarity (companionship in prison, trust, and getting familiar with someone in the cell, at the yard, at work in jail or in the sport room of the jail), 2) aggressiveness (curse, mockery, ridicule, threat, harassment, physical insult, harm, criticism on ability, character, milieu/background and appearance), 3) appreciation/socialization (acceptance of better physical situation and best friendship).

The network variables, in part based on tested questionnaire [24], have been calculated through Visone and further processed through SPSS conducting Pearson correlation. The aim of this bivariate correlation was to depict even the effects of possible outliers in order to make the sensitivity of the tested indicators more discernible and simultaneously to offer an overview of the correlations (dependence or independence between variables).

Classes of prisoners and not of normal students (free citizens) are selected for this research, because the prisoners are everyday "tried" under conditions of institutional pressure (lack of freedom and stable constellation of individuals). Thus, the relations of familiarity, aggressiveness and appreciation/socialization become more perceivable. Also, under these conditions certain critical incidents (e.g. extreme cases of accumulated threat) constitute outliers which are detected by the parametric Pearson test.

\subsection{Operationalizing the "Idiosyncrasy-" and the "Rationality-Based" Reaction}

Indicators combining closeness (as indicator of influence) and betweenness (as indicator of transferring information) in order to differentiate the really influential who imposes selected information as salient from the "postman" who just distribute it (pure salient actor = closeness-betweenness) [25].

In extension of this concept, three indicators have been applied on: 1) criticism (as a sum of critical comments on character, appearance, abilities and milieu/background) and 2) threat. These two forms of relation are selected to be examined as main variables interacting with the others, because these two variables are considered to be of greatest importance for the prison life according to explorative interviews conducted with wardens and prisoners. More precisely, according to the explorative interviews, criticism seems to be an easily practicable aggressiveness in the everyday life conditioning the general climate and behavior among prisoners while the threat is the most critical of the usual power tactics employed in the jail.

These three indicators are based on classical indicators of network analysis (particularly of centrality analysis), namely outdegree, indegree, status (meaning here the Katz status formula), pagerank and authority, and are the following ones:

1) Superficial behavior (SB)

$$
\mathrm{SB}=\text { Outdegree }
$$

This is classically measured as percentage of outgoing relations departing from a node of the number of total existent relations of a particular type (e.g. criticism or threat) within a completely analyzed network

2) Incremental behavior (IB)

$$
\mathrm{IB}=(4 \times \text { outdegree })-(\text { indegree }+ \text { status }+ \text { pagerank }+ \text { authority })
$$

3) Proportional behavior (PB)

$$
\mathrm{PB}=\frac{4 \times \text { outdegree }+1}{\text { indegree }+ \text { status }+ \text { pagerank }+ \text { authority }+1}
$$

The indegree is measured similarly to outdegree but it concerns received and not outgoing actions (e.g. of criticism or threat). Status and pagerank depict hierarchical situations emerging through successively accumulated or distributed influence of a particular relation from node to node. Authority points out the eminence level (qualified competitiveness) of each node in attractiveness in a particular type of relation [17] [19]. In general, these classical four indicators measure received actions (in contrast to outdegree), and their formulas of these classical four indicators which are as a rule scaled in \%, are well-known and easily to be found in numerous articles and websites. Thus, they will not be presented in this paper.

The indicators 2 and 3 are newly suggested by the authors. They are expected to allow revealing certain types of aggressiveness, which are not only quantitatively but also qualitatively different from aggressiveness expressed through outdegree. Qualitative difference is also expected to exist between IB and PB. 
Particularly, outdegree can be interpreted as a simplified indicator of the intensity of outgoing relations of each prisoner (e.g. criticism or threat) to the first-contacted persons. Thereby, it implies thus independence from any accumulated, deep-rooted structures formed in the network, and, thereby, superficiality in the behavior of a prisoner. Moreover, the outdegree is the inverted structure of indegree which has been used as an indicator of incidental-superficial contacts in contrast to other classical network indicators such as Katz status, pagerank or authority [19]. In other words, the outdegree may reasonably be regarded as an indicator of superficiality in practicing aggressiveness (exactly as the indegree is an indicator of superficial targeting for aggressiveness).

The main element of superficiality lies in the fact that outdegree indicates how aggressive one is without considering whether he is attacked or not. Therefore, there is a point in suggesting a more insightful indicator which will show the pure aggressiveness of someone, namely the aggression he practices without being attacked. Such aggressiveness will be unprovoked and will be purely generated by the character of a prisoner and not by instant incidences. Simultaneously, aggression which causes no aggressive reaction by others appears again to have a pure existence as a demonstrative or symbolic action of dominance. In any case, being aggressive without being attacked shows a pure situation of dominance or of aggression derived from the inmates' character (e.g. desire for dominance or revenge) and not from a need of instant defense to actual conditions.

The IB is, thus, an indicator of pure behavior, particularly of aggressiveness. Indeed, IB is maximized, when indegree $=$ status $=$ pagerank $=$ authority $=0$, depicting a situation of absolutely unprovoked or "untrammeled" (without resistance accepted) aggressiveness. The PB is also an indicator of pure behavior as well, which is similarly maximized, when exogenous (received) aggression is 0 (indegree $=$ status $=$ pagerank $=$ authority $=0$ ) . To make the sense of purity more clear, it can be stated that both indicators measure to what extent the aggression tends to be purely derived from the initiative of a particular node or is triggered or justified by external incidents of aggression. In this sense, the indicators 2 and 3 are considered to show purity of aggression. In this case, "purity” could also be alternatively characterized as spontaneity.

Provided that all the five classical indicators (out- and in-degree, status, pagerank and authority) are scaled in percentage (\%), then the IB can fluctuate from -400 to 400 (or from -4 to 4 , if the five indicators are reduced to the unit). The PB can fluctuate from $1 / 401=0.0025$ to 401 (or from $1 / 5=0.2$ to 5 , respectively).

Now it is understandable that the outdegree is multiplied with the coefficient " 4 " in IB and PB in order to balance the fourfold weight of the (four) indicators at nominator, as the maximal possible value of each of all these indicators (out-, in-degree, status, pagerank, authority) is 100\%. Thus, using the coefficient 4 for outdegree, the IB $=0$ and the $\mathrm{PB}=1$ when practicing aggression (outdegree) obtains the maximal possible value (100\%) and the received aggression is maximal (100\%) too from any point of view: incidentally (indegree $=100 \%$ ), accumulatively (status $=100 \%$ ), distributively (pagerank $=100 \%$ ), and eminently (authority $=100 \%$ ).

The additive " +1 " at the nominator of PB is useful in order to avoid infinities. The additive " +1 " is put at the numerator in order to balance the additive " +1 " at the nominator.

Now, it is of importance to amplify what IB and PB practically mean, in order to understand the qualitative difference between each other.

If, hypothetically, an inmate has IB = constant and $>0$, then this inmate presents a tendency to merely remain more aggressive than the others, independently of their aggressiveness. E.g., when the minuend $(4 \mathrm{X}$ outdegree) $=$ 10 and the subtrahend (indegree + status + pagerank + authority) $=5$, then IB $=5$. When the values of minuend and subtrahend become 15 and 10, 55 and 50, 78 and 74, 305 and 300 etc, the IB will remain constant (=5). Thus, the aggressive inmate with this constant IB, is just an aggressive inmate independent of the attacks he receives by the others. He presents a noticeable over-extroversion of aggression because of his idiosyncrasy. If his IB = constant and $<0$, it is a similar idiosyncrasy-driven case, but introvert.

If, hypothetically, an inmate has $\mathrm{PB}=$ constant and $>1$, then this inmate presents a tendency not merely to be more aggressive than the others who attack to him but to be proportionally aggressive. E.g., if PB = 5 constantly, then this means that the inmate steadily practices 5 times more aggression than he receives by the others. When the nominator (receiving aggression) is 10, then the numerator (practicing aggression) will be 50, or, respectively, 12 and 60, 40 and 200, etc. In this case, the inmate will apply a tactic of premeditatedly dominant over-extroversion of aggression. This tendency of dominance is not idiosyncrasy-driven as in the case of constant IB but it is rationality-driven, aiming at stably maintaining dominance depending on the intensity of the attacks of the others. When $\mathrm{PB}=$ constant and $<1$, it is a similar rationality-driven case, but introvert. In this sense, the IB expresses just an incremental while the $\mathrm{PB}$ a more thoughtful, proportional, behavior.

When the IB of inmates is increasing, then the inmates tend just to be more aggressive than others motivated 
by idiosyncrasy rather than by need of proportionally defensive or imposing reaction. When the PB of inmates is increasing, the tendency of impose or to defend themselves in a more premeditated and rational way considering the others' action is evident.

After this explication, it is also obvious that such an operationalization of network-structured behavior is not only a matter of (measuring) method but also a matter of theorizing. It is inevitably a case of structuring theoretical basis (idiosyncrasy vs. rationality) through IB and PB, though they are at first suggested as methodical tools.

\section{Results and Discussion}

The class A and B included 23 and 12 inmates, respectively. Generally, there is an obvious differentiation in hierarchies, as it is presented in Figure 1.

In Table 1 it is noticeable that numerous significant correlations occur between SB in criticism and other types of structure of familiarization (0.376 to 0.559$)$ or of aggressiveness ( 0.340 to 0.670$)$ or of appreciation/socialization (0.376 to 0.370 ).

At first place, it is remarkable that the SB in criticism is not necessarily incompatible with companionship within prison (insign. coefficient 0.127 ). The SB in criticism seems to take place among several inmates mutually and is not regarded as an anti-social behavior.

This SB seems to be enhanced by the familiarization within other inmates taking place inside the cell or at the cell yard or at the main yard or at the sport room. Thus, familiarization makes someone "easy target" for criticism. Otherwise, his "weaknesses" remain unknown.

Curse, mockery, ridicule and tendency to harm or harass other inmates are convergent with the SB. Thus, there seems to be no isolation of SB as autonomous aggressive practice, but it rather appears combined with or subsequent to various other structures of (verbal or physical) aggressiveness. Thereby, a generalization of aggressiveness, expressed through criticism, is obvious. The SB is apparently the "corner stone" of aggressiveness.

Additionally, the SB seems to be exerted to inmates who are considered to be in "better physical" situation or to be "best friends". Namely, they are criticized either because of jealousness or as "easy target" due to exploitation of tolerance on the basis of friendship.

What happens, however, in case of inmates who present over-extroversion in criticism? In Table 1, over-extrovert inmates tend to adopt radically different behavioral patterns. In contrast to the SB, the incremental behavior (IB) in criticism seems to be destructive for the companionship (-0.405). Surprisingly, the proportional

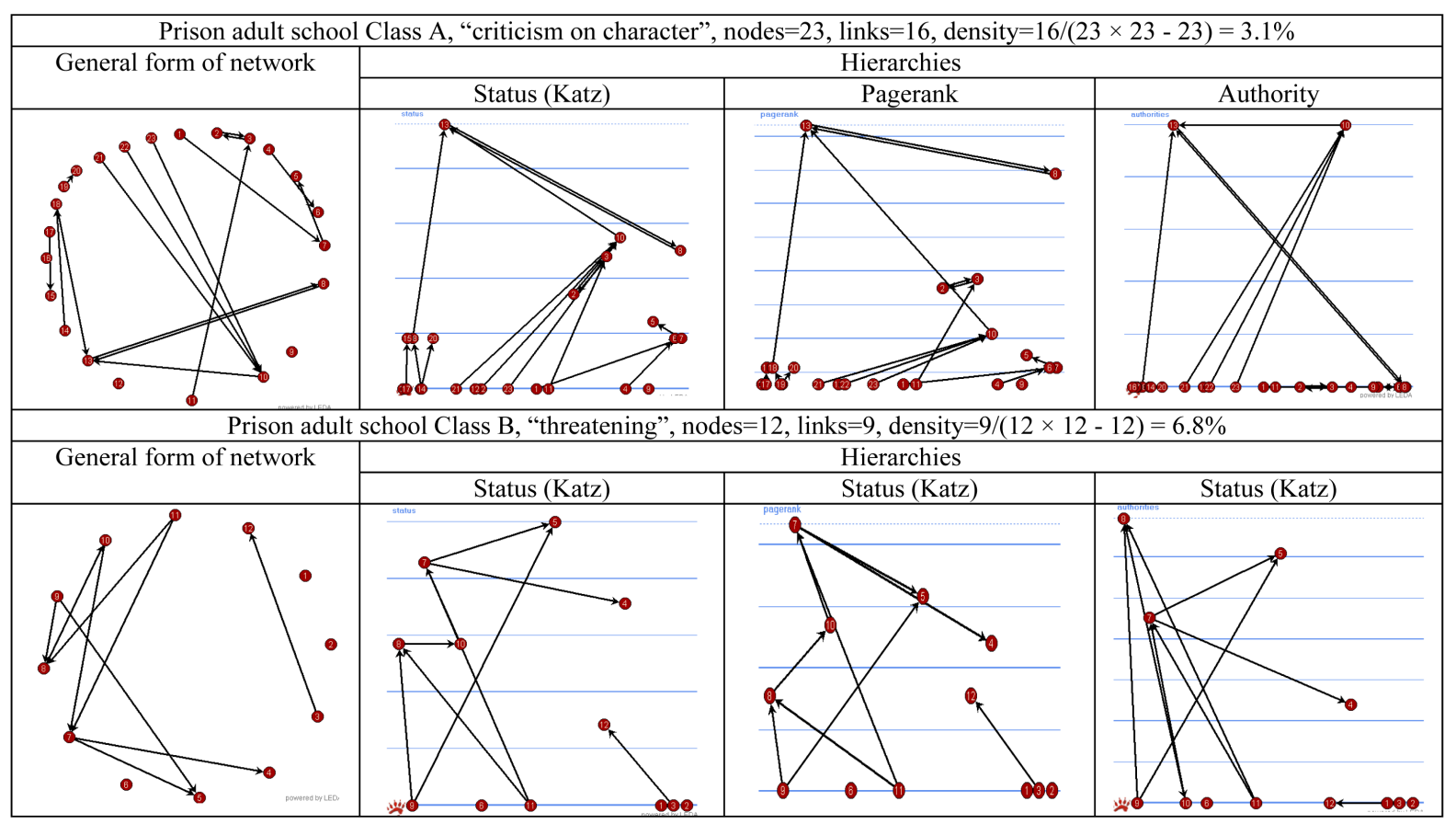

Figure 1. Examples of completely analyzed networks of prison adult school classes. 
Table 1. Criticism (considering outliers with Pearson).

\begin{tabular}{|c|c|c|c|c|}
\hline & \multirow[b]{2}{*}{ Pearson } & \multirow{2}{*}{$\begin{array}{c}\begin{array}{c}\text { Superficiality } \\
\text { (outdegree) }\end{array} \\
\text { Superficial behavior } \\
\text { (SB) in criticism }\end{array}$} & \multicolumn{2}{|c|}{ Behavioral purity (over-extroversion) } \\
\hline & & & $\begin{array}{l}\text { Incremental behavior } \\
\text { (IB) in criticism } \\
\text { (difference between } \\
\text { received and practiced } \\
\text { aggressiveness) }\end{array}$ & $\begin{array}{l}\text { Proportional behavior } \\
\text { (PB) in criticism } \\
\text { (ratio between received } \\
\text { and practiced } \\
\text { aggressiveness) }\end{array}$ \\
\hline \multirow{28}{*}{ 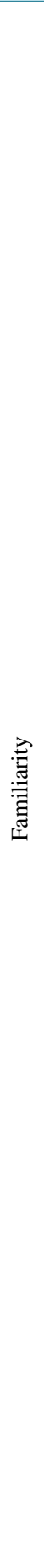 } & $\begin{array}{l}\text { Preferred for companionship in prison } \\
\text { (pagerank) }\end{array}$ & 0.127 & -0.405 ( ) & -0.082 \\
\hline & & 0.467 & 0.016 & 0.638 \\
\hline & $\begin{array}{l}\text { Being familiar with inmates } \\
\text { in cell (outdegree) }\end{array}$ & $0.376\left({ }^{*}\right)$ & 0.066 & -0.133 \\
\hline & & 0.026 & 0.704 & 0.447 \\
\hline & $\begin{array}{l}\text { Other inmates are familiarized with } \\
\text { him in cell (pagerank) }\end{array}$ & $0.469\left(^{* *}\right)$ & 0.009 & -0.136 \\
\hline & & 0.004 & 0.960 & 0.437 \\
\hline & $\begin{array}{l}\text { Being familiar with other inmates } \\
\text { in cell yard (outdegree) }\end{array}$ & $0.439\left(^{* *}\right)$ & $0.343\left(\left(^{*}\right)\right.$ & -0.007 \\
\hline & & 0.008 & 0.044 & 0.967 \\
\hline & $\begin{array}{l}\text { Other inmates are familiarized with } \\
\text { him in cell yard (status) }\end{array}$ & $0.344\left({ }^{*}\right)$ & 0.120 & -0.086 \\
\hline & & 0.043 & 0.492 & 0.623 \\
\hline & $\begin{array}{l}\text { Other inmates are familiarized with } \\
\text { him in cell yard (authority) }\end{array}$ & $0.337\left(^{*}\right)$ & 0.073 & 0.065 \\
\hline & & 0.048 & 0.677 & 0.711 \\
\hline & $\begin{array}{l}\text { Other inmates are familiarized with } \\
\text { him at the main yard (indegree) }\end{array}$ & $0.593\left(^{* *}\right)$ & 0.218 & -0.120 \\
\hline & & 0.000 & 0.208 & 0.492 \\
\hline & $\begin{array}{l}\text { Other inmates are familiarized with } \\
\text { him at the main yard (status) }\end{array}$ & $0.533\left({ }^{* *}\right)$ & 0.230 & -0.134 \\
\hline & & 0.001 & 0.183 & 0.443 \\
\hline & $\begin{array}{l}\text { Other inmates are familiarized with } \\
\text { him at the main yard (authority) }\end{array}$ & $0.553\left(^{* *}\right)$ & 0.186 & -0.021 \\
\hline & & 0.001 & 0.284 & 0.906 \\
\hline & $\begin{array}{l}\text { Other inmates are familiarized with } \\
\text { him at the main yard (pagerank) }\end{array}$ & $0.388\left(\left(^{*}\right)\right.$ & 0.298 & -0.065 \\
\hline & & 0.021 & 0.082 & 0.710 \\
\hline & $\begin{array}{l}\text { Other inmates are familiarized with } \\
\text { him at the sport room (indegree) }\end{array}$ & $0.438\left(^{* *}\right)$ & -0.168 & -0.246 \\
\hline & & 0.008 & 0.334 & 0.154 \\
\hline & $\begin{array}{l}\text { Being familiar with inmates at } \\
\text { the sport room (outdegree) }\end{array}$ & $0.477\left(^{* *}\right)$ & 0.046 & -0.029 \\
\hline & & 0.004 & 0.794 & 0.868 \\
\hline & $\begin{array}{l}\text { Other inmates are familiarized with him at } \\
\text { the sport room (status) }\end{array}$ & $0.353\left(^{*}\right)$ & -0.171 & -0.252 \\
\hline & & 0.037 & 0.326 & 0.144 \\
\hline & $\begin{array}{l}\text { Other inmates are familiarized with him at } \\
\text { the sport room (authority) }\end{array}$ & $0.559\left({ }^{* *}\right)$ & -0.031 & -0.119 \\
\hline & & 0.000 & 0.860 & 0.495 \\
\hline
\end{tabular}




\section{Continued}

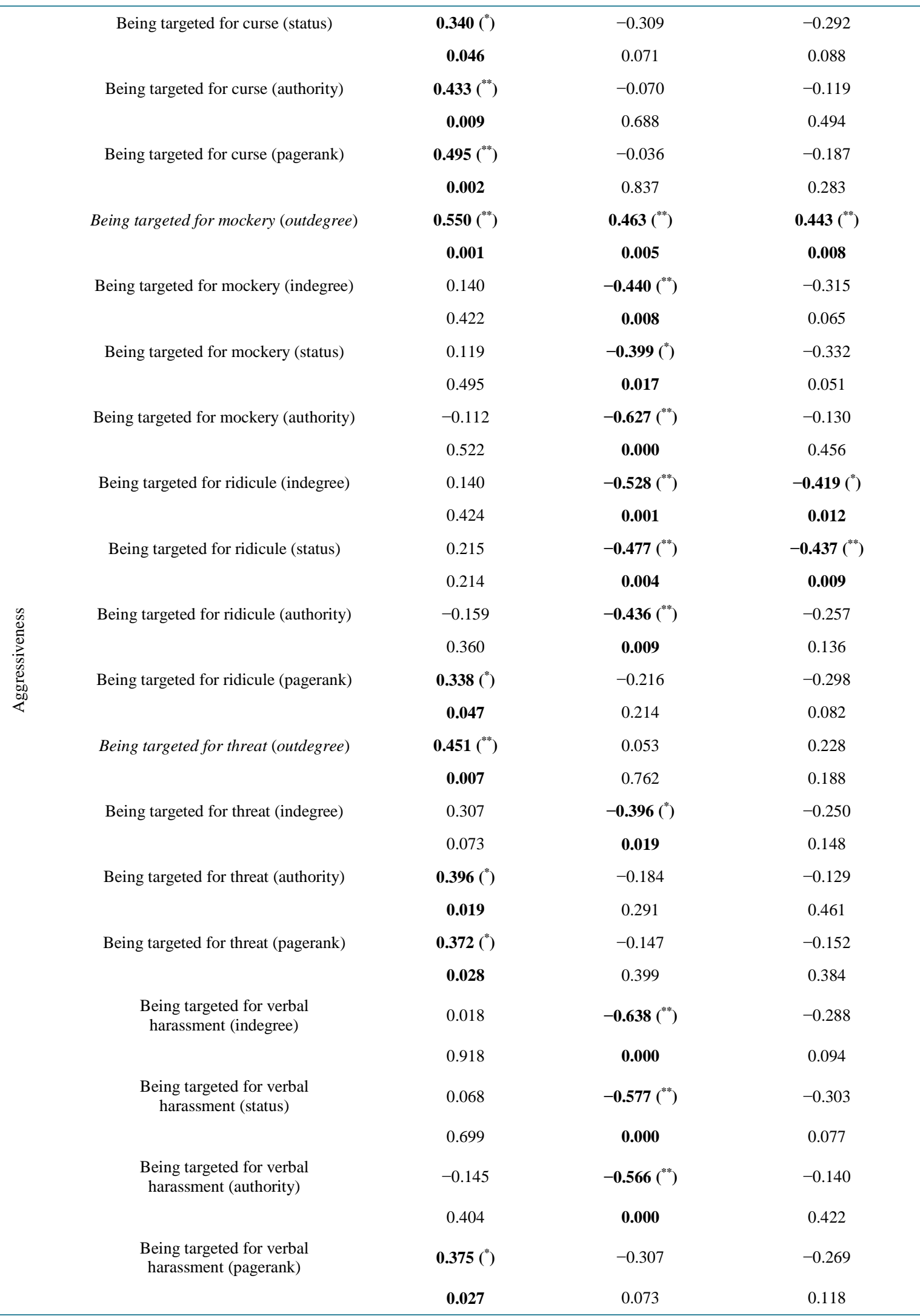




\section{Continued}

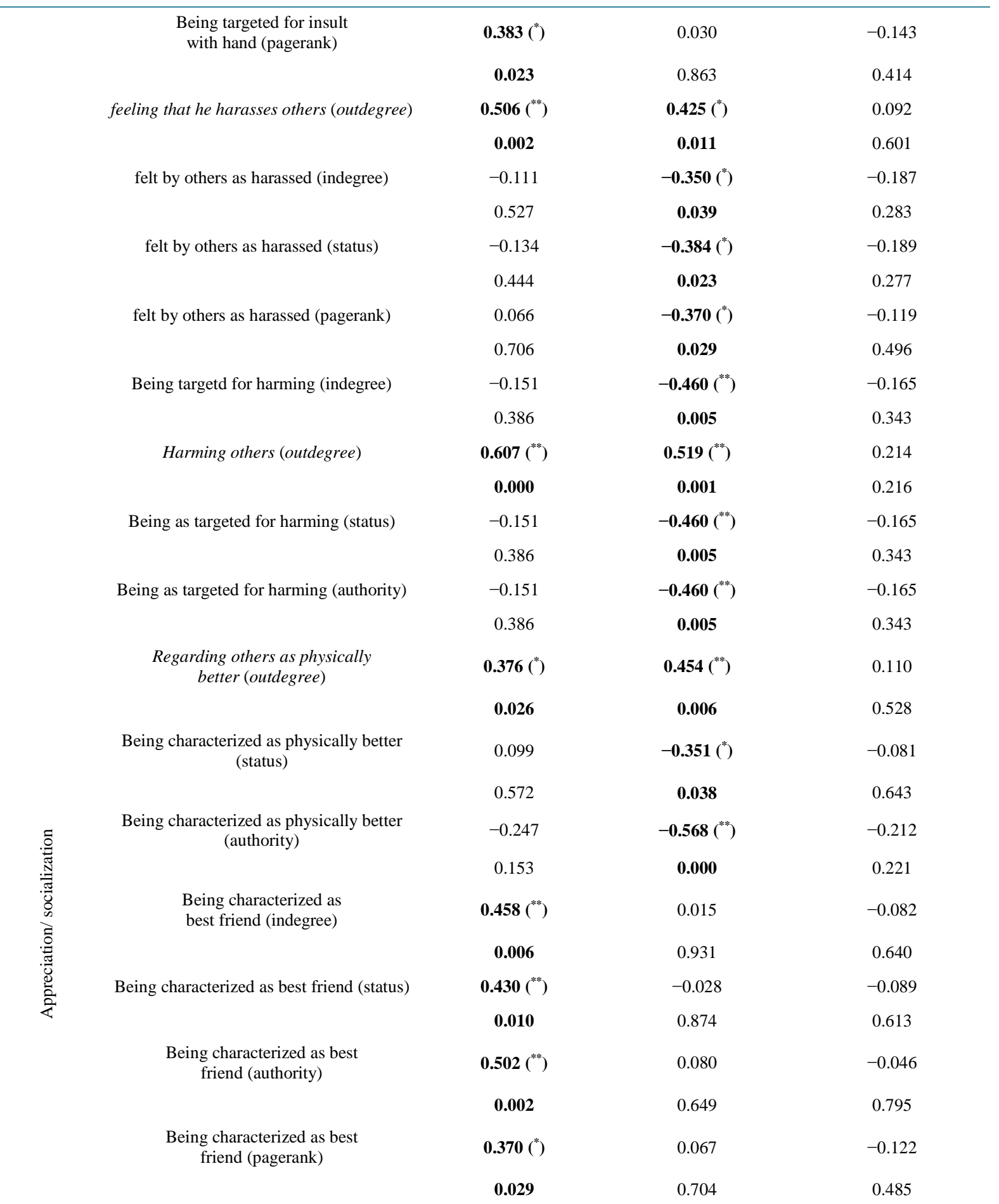

${ }^{* *}$ Correlation is significant at the 0.01 level (2-tailed). ${ }^{*}$ Correlation is significant at the 0.05 level (2-tailed).

behavior (PB) in criticism appears not to be destructive for the companionship in prison (insign. - 0.082) exactly as in the case of SB.

Why neither SB nor PB are destructive for the companionship? The SB has incidental character and can be practiced more or less by any prisoner occasionally. So, it is regarded as a normal rather than a damnable or anti-social 
behavior. However, intensifying aggressiveness in relation to the others' aggressiveness shows a tactic of continuously adjusting behavior in the sense or proportionality principle. This is also a generally acceptable tactic of defense. For this reason, the PB is regarded as acceptable as SB, in contrast to IB which is discerned as strongly individualistic and lustful for dominance, and subsequently unacceptable, disturbing and anti-social.

Furthermore, the IB is positively related with the outdegree of familiarization (0.343) and of mockery (0.436), negatively related with the indegree, status and authority of mockery $(-0.440$ to -0.627$)$. This can be attributed to a willing to exploit the try of familiarization for assuring more tolerance to criticism. Simultaneously, exerting criticism is often mixed with exerting mockery, while discouraging mockery exerted by others. High IB in criticism is also defensive against ridicule $(-0.528$ to -0.436$)$.

Similarly, the IB in criticism seems also to protect against other aggressive actions such as threat, harassment and harming $(-0.396$ to -0.460$)$, while it enhances aggressive attempts and attitudes $(0.425,0.519)$.

Moreover, a prisoner who considers others to be in better physical situation than him $(0.454)$ tends to be critically over-extrovert to them. On the contrary, when he is appreciated by others regarding his physical situation $(-0.351,-0.568)$, he does not need to be over-critical toward them.

Comparing SB with IB, it is remarkable that the former is only positively correlated both with exerting and receiving various forms of aggressiveness. Thereby, the SB in criticism exerted by a prisoner seems to be his subsequent reaction to aggressiveness by thirds, a supportive means for his own aggressiveness (outdegree of other forms of aggressiveness), and a behavior enhanced due to less or more intimacy generated through familiarization and socialization.

On the other hand, the IB (tendency of incrementally criticizing without being criticized) is significantly- and negatively-correlated, as a rule, with structures different than those which are significantly correlated with the SB.

Similarly to the SB, IB in criticism is also supportive for other forms of aggressiveness. However, the IB does not depend (insign. coefficients) on most familiarization parameters. Thus, a prisoner with high IB is critically extroverted against any other prisoner, independent of being familiarized with him or not. This is evidence that the IB is more strongly determined by the individual idiosyncrasy than the social interactions within prison. Additionally, the IB appears to be strongly contradicting (significant negative coefficients) to several forms of received aggressiveness and not just to be of "symbolic" response as the SB seems to be. Certain form of reputation gained in prison (recognition of better physical situation by other prisoners) seems to be an antidote to IB, or, inversely, the IB is vengeance against the lack of recognition. In any case, the incremental behavior reveals an obvious individualism and a lust for power.

The PB is a much more selective indicator as it appears much less significant coefficients. Only in case of supporting outgoing mockery (0.443) it seems that a prisoner tends to react not merely superficially on the basis of incidences or incrementally on the basis of his idiosyncrasy but also adopting his response proportionally to the response of others. Being target for ridicule $(-0.419,-0.437)$ seems also to be significantly contradicting to PB. Thereby, this form of verbal aggressiveness is obviously a strong discourage of being critical and drastically leads up to a re-adjusting of critical behavior.

The results regarding threat are presented in the Table 2. In general, the sensitivity of the respective indicators seems to be similar to this appearing in the case of criticism (Table 1). The outdegree of threat presents a characteristic superficiality as it seems to be combined with numerous relations in prison (0.350 to 0.405$)$. At first it is noticeable that threatening seems to be encouraged by becoming familiar through work $(0.400)$, to make a synergy with various forms of criticism $(0.408,0.384,0.399)$ and to be accompanied also by curse $(0.699)$ and harm (0.391).

Simultaneously, the rest relational forms that are positively correlated with practicing superficial threatening, depict received actions, namely preferability for companionship, trustworthiness, being target of criticism, curse or mockery and even recognition of better physical situation or best friend. In other words, the best companion or friend, or a prison recognized as physically better or trustworthy tends not to estimate this reputation but rather to exploit this reputation in order to threat. The threat seems also to be a reaction to aggressiveness.

High IB, namely an over-extroversion in threatening, which depends on idiosyncrasy and not on proportional behavior to external stimuli, seems to discourage others from becoming familiar or recognize the threater as best friend but also from being aggressive to him $(-0.348$ to -0.380$)$. However, this idiosyncratic over-extroversion to threat seems to find a synergy or simultaneous expression with criticizing abilities $(0.358)$ as this may satisfy egoism. The individualistic pattern of threatening behavior seems rather to maintain impulsive than strategic 
Table 2. Threat (considering outliers with Pearson).

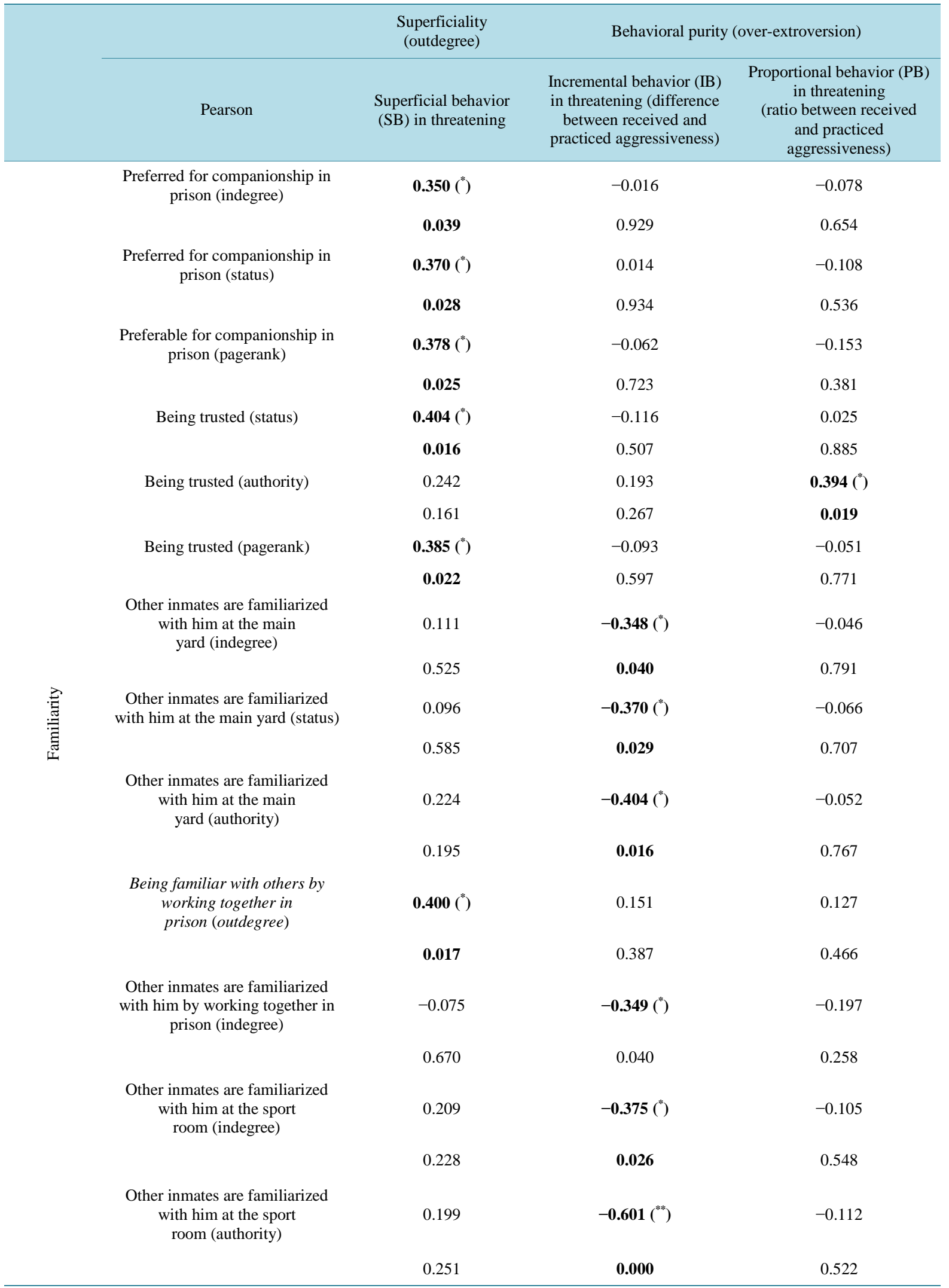




\section{Continued}

\begin{tabular}{|c|c|c|c|c|}
\hline & $\begin{array}{l}\text { Being targeted for criticism about } \\
\text { abilities (indegree) }\end{array}$ & -0.033 & $-0.499\left(^{* *}\right)$ & -0.225 \\
\hline & & 0.852 & 0.002 & 0.194 \\
\hline & $\begin{array}{c}\text { Criticizing others about abilities } \\
\text { (outdegree) }\end{array}$ & $0.408\left(^{*}\right)$ & $0.358\left(^{*}\right)$ & 0.320 \\
\hline & & 0.015 & 0.035 & 0.061 \\
\hline & $\begin{array}{l}\text { Being targeted for criticism about } \\
\text { abilities (status) }\end{array}$ & -0.073 & $-0.535\left(^{* *}\right)$ & -0.237 \\
\hline & & 0.678 & 0.001 & 0.171 \\
\hline & $\begin{array}{l}\text { Being targeted for criticism about } \\
\text { abilities (authority) }\end{array}$ & 0.227 & $-0.438\left(^{* *}\right)$ & -0.023 \\
\hline & & 0.190 & 0.008 & 0.894 \\
\hline & $\begin{array}{l}\text { Being targeted for criticism about } \\
\text { abilities (pagerank) }\end{array}$ & -0.030 & $-0.457\left(^{* *}\right)$ & -0.302 \\
\hline & & 0.863 & 0.006 & 0.078 \\
\hline & $\begin{array}{l}\text { Being targeted for criticism about } \\
\text { character (status) }\end{array}$ & 0.221 & $-0.476\left(^{* *}\right)$ & -0.192 \\
\hline & & 0.202 & 0.004 & 0.269 \\
\hline & $\begin{array}{l}\text { Being targeted for criticism about } \\
\text { character (authority) }\end{array}$ & $0.423\left(^{*}\right)$ & -0.293 & -0.089 \\
\hline & & 0.011 & 0.087 & 0.611 \\
\hline & $\begin{array}{l}\text { Being targeted for criticism about } \\
\text { character (pagerank) }\end{array}$ & 0.126 & $-0.510\left(^{* *}\right)$ & -0.171 \\
\hline$\stackrel{8}{8}$ & & 0.472 & 0.002 & 0.327 \\
\hline 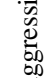 & $\begin{array}{l}\text { Criticizing others about their } \\
\text { milieu or background }\end{array}$ & $0.384\left(^{*}\right)$ & $-0.421\left(^{*}\right)$ & 0.094 \\
\hline & & 0.023 & 0.012 & 0.592 \\
\hline & $\begin{array}{l}\text { Being targeted for criticism about } \\
\text { milieu or background (authority) }\end{array}$ & $0.371\left(^{*}\right)$ & 0.111 & -0.029 \\
\hline & & 0.028 & 0.526 & 0.867 \\
\hline & $\begin{array}{l}\text { Criticizing others about } \\
\text { appearance (outdegree) }\end{array}$ & $0.399\left(^{*}\right)$ & 0.030 & 0.183 \\
\hline & & 0.018 & 0.864 & 0.293 \\
\hline & Cursing others (outdegree) & $0.699\left(^{* *}\right)$ & 0.263 & 0.319 \\
\hline & & 0.000 & 0.128 & 0.062 \\
\hline & $\begin{array}{l}\text { Being targeted for } \\
\text { curse (indegree) }\end{array}$ & 0.192 & $-0.515\left(^{* *}\right)$ & -0.326 \\
\hline & & 0.270 & 0.002 & 0.056 \\
\hline & Being targeted for curse (status) & 0.204 & $-0.641\left(^{* *}\right)$ & -0.304 \\
\hline & & 0.239 & 0.000 & 0.076 \\
\hline & $\begin{array}{l}\text { Being targeted for curse } \\
\text { (authority) }\end{array}$ & 0.152 & $-0.722\left(^{* *}\right)$ & -0.154 \\
\hline & & 0.384 & 0.000 & 0.377 \\
\hline & $\begin{array}{l}\text { Being targeted for } \\
\text { curse (pagerank) }\end{array}$ & 0.167 & $-0.560\left(^{* *}\right)$ & -0.176 \\
\hline & & 0.339 & 0.000 & 0.312 \\
\hline & $\begin{array}{l}\text { Being targeted for } \\
\text { mockery (authority) }\end{array}$ & $0.340\left(^{*}\right)$ & 0.017 & -0.142 \\
\hline
\end{tabular}




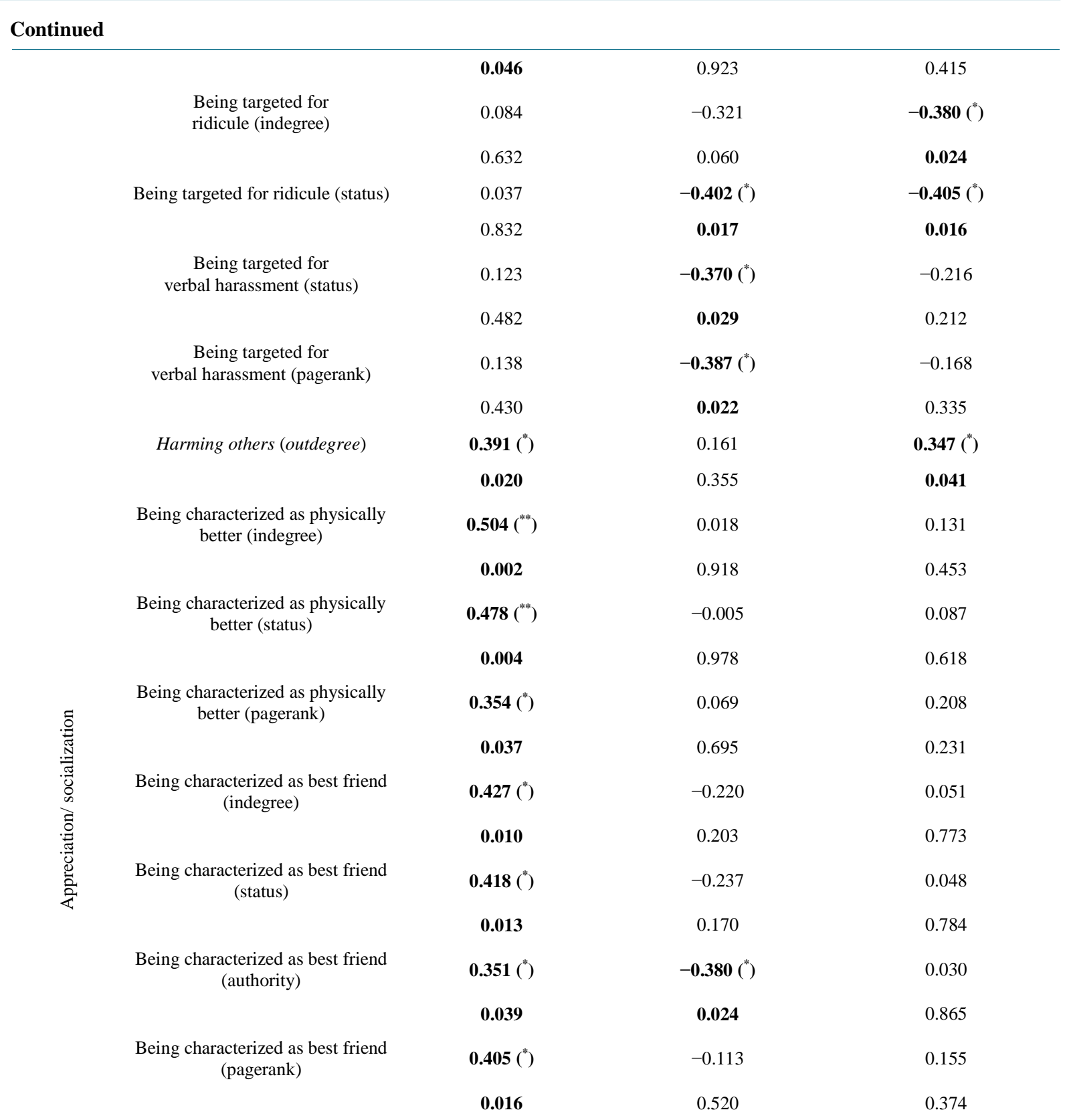

${ }^{*}$ Correlation is significant aot the 0.05 level (2-tailed). ${ }^{* *}$ Correlation is significant at the 0.01 level (2-tailed).

motive. It is also a quite sensitive indicator like superficiality.

The PB in threat (Table 2) proves to be the least sensitive indicator once again as in the case of criticism (Table 1). This environment-dependent threatening seems to be quite strategic as it depends on trustworthiness (0.394) which enables intimacy and ability to (mis)lead, harming (0.347) which shows a serious purpose of threatening. Under these conditions, the threatening person cannot be seen as ridiculous $(-0.380,-0.405)$.

\section{Conclusions}

Indicators of superficial and pure roles, particularly incremental and proportional behavior, have been applied in two forms of verbal aggressiveness, namely in criticism and threatening. The results were similar in both forms. The superficial behavior (SB: just outdegree of verbal aggressiveness) seems to be a quite sensitive indicator, as it presents correlations with various other relational forms of familiarity, aggressiveness and appreciation/socia- 
lization.

It is interesting that the incremental behavior (IB: difference of received from outgoing relations) is also a sensitive indicator. However, it reveals quite different results, as it is significantly and negatively correlated as a rule with the rest behavioral dimensions of familiarity, aggressiveness and appreciation/socialization, which appear to be independent from superficial behavior. This practically means that the pure aggressiveness (in terms of difference) seems to be related with quite different causes and/or occasions than the superficial aggressiveness. Provided that the pure incremental behavior is likely to be at first place driven by the idiosyncrasy rather than by exogenous factors, the negative correlations can be understood as a restrictive impact of the environment on the endogenous tendencies of the individuals. In other words, the indicator of incremental aggressiveness seems to express and measure a completely different entity/notion than the outdegree. It apparently measures a reactive occurrence of ego. The negative correlations can be realized as a "tug of war" between prisoner's ego and its environment (other prisoners).

In other words, the incremental aggressive behavior seems to be a trait of privacy and individualism of a prisoner. It could also be regarded as an original core of his personality, which is tested within a straining interaction with the social environment of the prison.

If the incremental aggressiveness is participating in such a "tug of war", then the superficial behavior, which is as a rule positively correlated with the other forms of relations (familiarity, aggressiveness, and appreciation/socialization), could reasonably be regarded as a reaction dictated by the everyday reciprocity patterns of the prison. The superficial aggressiveness seems rather to be a behavioral pattern accompanying a numerous of "constructive" or "destructive", "friendly" or "unfriendly" behaviors of prisoners, making them more "existent" and "respectable" within the jail. Thus, superficial aggressiveness seems to be an effect of learnt behavior while incremental aggressiveness seems to be immanent.

Finally, the proportional aggressive behavior is a quite insensitive indicator, as it depends only on a few behavioral variables. As it has been argued, this indicator expresses a rational strategy of adaptability. Thus, it characteristically differs from the indicators of superficiality (expressing reciprocity patterns) and of the incremental aggressiveness (expressing individualism).

\section{References}

[1] Rancer, A.S. and Avtgis, T.A. (2014) Argumentative and Aggressive Communication. 2nd Edition, Peter Lang, New York.

[2] Infante, D.A. (1987) Aggressiveness. In: McCroskey, J.C. and Daly, J.A., Eds., Personality and Interpersonal Communication, Sage, Newbury Park, CA, 157-192.

[3] Infante, D.A. and Rancer, A.S. (1982) A Conceptualization and Measure of Argumentativeness. Journal of Personality Assessment, 46, 72-80. http://dx.doi.org/10.1207/s15327752jpa4601_13

[4] Infante, D.A. and Wigley, C.J. (1986) Verbal Aggressiveness: An Interpersonal Model and Measure. Communications Monographs, 53, 61-69. http://dx.doi.org/10.1080/03637758609376126

[5] Infante, D.A., Sabourin, T.C., Rudd, J.E. and Shannon, E.A. (1990) Verbal Aggression in Violent and Nonviolent Marital Disputes. Communication Quarterly, 38, 361-371. http://dx.doi.org/10.1080/01463379009369773

[6] Infante, D.A., Riddle, B.L., Horvath, C.L. and Tumlin, S.A. (1992) Verbal Aggressiveness: Messages and Reasons. Communication Quarterly, 40, 116-126. http://dx.doi.org/10.1080/01463379209369827

[7] Myers, S.A., Brann, M. and Martin, M.M. (2013) Identifying the Content and Topics of Instructor Use of Verbally Aggressive Messages. Communication Research Reports, 30, 252-258.

http://dx.doi.org/10.1080/08824096.2013.806260

[8] Bekiari, A. (2012) Perceptions of Instructor's Verbal Aggressiveness and Physical Education Students' Affective Learning. Perceptual \& Motor Skills, 115, 325-335. http://dx.doi.org/10.2466/06.11.16.PMS.115.4.325-335

[9] Edwards, C. and Myers, S.A. (2007) Perceived Instructor Credibility as a Function of Instructor Aggressive Communication. Communication Research Reports, 24, 47-53.

[10] Infante, D.A., Myers, S.A. and Buerkel, R.A. (1994) Argument and Verbal Aggression in Constructive and Destructive Family and Organizational Disagreements. Western Journal of Communication (Includes Communication Reports), 58, 73-84. http://dx.doi.org/10.1080/10570319409374488

[11] Infante, D.A. and Rancer, A.S. (1996) Argumentativeness and Verbal Aggressiveness: A Review of Recent Theory and Research. Communication Yearbook, 19, 319-352. 
[12] Mazer, J.P. and Stowe, S.A. (2015) Can Teacher Immediacy Reduce the Impact of Verbal Aggressiveness? Examining Effects on Student Outcomes and Perceptions of Teacher Credibility. Western Journal of Communication, (ahead-ofprint), 1-17.

[13] Bekiari, A. (2014) Verbal Aggressiveness and Leadership Style of Sports Instructors and Their Relationship with Athletes’ Intrisic Motivation. Creative Education, 5, 114-121. http://dx.doi.org/10.4236/ce.2014.52018

[14] Myers, S.A. and Knox, R.L. (2000) Perceived Instructor Argumentativeness and Verbal Aggressiveness and Student Outcomes. Communication Research Reports, 17, 299-309. http://dx.doi.org/10.1080/08824090009388777

[15] Myers, S.A. and Rocca, K.A. (2001) Perceived Instructor Argumentativeness and Verbal Aggressiveness in the College Classroom: Effects on Student Perceptions of Climate, Apprehension, and State Motivation. Western Journal of Communication (Includes Communication Reports), 65, 113-137. http://dx.doi.org/10.1080/10570310109374696

[16] Schrodt, P. (2003) Students’ Appraisals of Instructors as a Function of Students’ Perceptions of Instructors’ Aggressive Communication. Communication Education, 52, 106-121. http://dx.doi.org/10.1080/03634520302468

[17] Bekiari, A. and Hasanagas, N. (2015) Verbal Aggressiveness Exploration through Complete Social Network Analysis: Using Physical Education Students' Class as an Illustration. International Journal of Social Science Studies, 3, 30-49. http://dx.doi.org/10.11114/ijsss.v3i3.729

[18] Bekiari, A. and Syrmbas, I. (2015) The Influence of Motivational Climate and Coaches’ Verbal Aggression on Athletes’ Satisfaction. British Journal of Education, Society \& Behavioural Science, 9, 318-329. http://dx.doi.org/10.9734/BJESBS/2015/17757

[19] Hasanagas, N. and Bekiari, A. (2015) Depicting Determinants and Effects of Intimacy and Verbal Aggressiveness Target through Social Network Analysis. Sociology Mind, 5, 162.

[20] Richmond, V.P. and Gorham, J. (1992) Communication, Learning, and Affect in Instruction. Burgess International Group, New York.

[21] Cabanac, M., Ramírez, J.M., Millana Cuevas, L.C., Toldos Romero, M.P. and Bonniot-Cabanac, M.C. (2008) The Pleasure of Aggressiveness among Inmates in Preventive and Longterm Detention. The Open Criminology Journal, 1, 19-26. http://dx.doi.org/10.2174/1874917800801010019

[22] McCorkle, R.C. (1992) Personal Precautions to Violence in Prison. Criminal Justice and Behavior, 19, 160-173. http://dx.doi.org/10.1177/0093854892019002004

[23] Anderson, C.M. and Rancer, A.S. (2007) The Relationship between Argumentativeness, Verbal Aggressiveness, and Communication Satisfaction in Incarcerated Male Youth. The Prison Journal, 87, 328-343. http://dx.doi.org/10.1177/0032885507304433

[24] Bekiari, A. and Digelidis, N. (2015) Measuring Verbal Aggressiveness in Sport and Education. International Journal of Physical Education, 4, 12-21.

[25] Hasanagas, N.D. (2014) Managing Information in Forest Policy Networks: Distinguishing the Influential Actors from the "Postmen". Forest Policy and Economics (in press). http://dx.doi.org/10.1016/j.forpol.2014.09.007 